\title{
Waves in Consumption with Interdependence among Consumers
}

\author{
Robin Cowan*, William Cowan** and Peter Swann*** \\ *University of Western Ontario, Canada and University of Maastricht, The Netherlands \\ $* *$ University of Waterloo, Canada \\ *** University of Manchester, UK
}

\begin{abstract}
This paper presents a model to analyze the development of consumption patterns when there are social interactions among consumers. In particular a consumer in this model recognizes three reference groups: a peer group of similar consumers with whom the consumer wishes to share consumption activities; a distinction group from which the consumer wishes to distinguish him- or herself; and an aspiration group, to which the consumer does not belong but wishes that he/she did, and with whom the consumer would like to share consumption activities. The interplay of aspiration and distinction can lead to "waves" in consumption. These can happen when, for example, the avantgarde consumption of up-market pioneers is copied by other types of consumer: as the latter aspire to emulate the former, the former in turn seek to distinguish themselves from these unwelcome companions by varying their consumption. In consequence a particular consumption activity may start up-market, an then gradually proceed down the social spectrum. More complex patterns with continuing cycles in consumption can also be found. The paper argues that this model is not only applicable to the consumption behaviour of an elite (or would-be elite) but is relevant in a wide range of consumption settings.
\end{abstract}

Keywords: Consumption, Evolutionary Theory, Interdependence, Externalities J.E.L.Codes: D11, D62

We acknowledge helpful discussions with Cristiano Antonelli, Stan Metcalfe, and Staffan Hultén, none of whom is responsible for any remaining errors. 


\section{Introduction}

The consumer of mainstream economic analysis is generally assumed to have fixed tastes, and to enjoy his or her consumption essentially in private. A wide body of literature has recognized, however, that consumer behaviour evolves over time, and that consumption is an inherently social activity. Indeed, many writers analyze these two phenomena together, because they believe that social interdependencies in consumption are one of the main agents for change in consumer behaviour. An individual's utility from consumption of certain goods is affected by the behaviour of other groups of consumers, and there are several aspects to this interdependence. Some activities become more desirable when they can be shared with a group of peers, and this associative motive plays an important role in the analysis of bandwagon behaviour (Liebenstein, 1950). Again, some activities become more desirable if they allow the consumer to emulate the consumption of an elite that he or she aspires to join. By contrast, some activities become more desirable when the individual can, through wealth or personal endowments, outshine his peers: Smith (1776) remarks that "the chief enjoyment of riches consists in the parade of riches", and this phenomenon was studied by Veblen (1899). Or equally, some distinctive activities are desirable because even if they do not cause the consumer to outshine any peers, they sustain a desire for distinction which Marshall (1920) and Senior (1844) described as, "a feeling which ... may be pronounced to be the most powerful of human passions".

The key to understanding these different effects is to recognise that the individual's consumption decisions can depend on the behaviour of specific groups, rather than on other consumers as a mass. In a general way, we can characterize these influences as arising from three specific groups: a peer group of similar consumers with whom the consumer wishes to share consumption activities; a distinction group from which the consumer wishes to distinguish himself/herself; and an aspiration group, to which the consumer does not belong but wishes that he/she did, and with whom the consumer would like to share consumption activities.

In this paper we make the convenient simplifying assumption that consumers are arrayed along a scalar "class spectrum", and the individual's concern with the consumption behaviour of other consumers depends on where he and they are located on this spectrum. In using the term "class" we do not invoke the traditional class concept of classical economics: rather, this is a convenient way to work with the association, distinction and aspiration groups referred to above. In general the consumer seeks to associate with those who are close in the "class" spectrum, to distinguish himself/herself from those who are below, and to emulate the consumption behaviour of those above. 
Of course in practice, it may be more appropriate to envisage consumers arrayed over a multi-dimensional class space, but for analytical simplicity a scalar representation is used here.

This paper develops a model of consumption in which peer, distinction and aspiration effects are central in determining individual consumer behaviour. From a model of individual decision-making we generate static and dynamic results on the distribution of the consumption of a good within a population of consumers. The paper is organized as follows. Section 2 surveys some of the literature that describes and analyzes interdependencies in consumption. Section 3 gives a brief illustration of some empirical examples where interdependencies in consumption can lead to waves in consumption. Such behaviour cannot readily be explained in an equilibrium model with fixed tastes. Section 4 then describes the model of consumption in detail, and presents results on equilibrium and on the dynamics of consumption. Section 5 illustrates the sorts of waves in consumption that the model can generate, and section 6 concludes.

\section{Literature on Demand with Inter-dependencies among Consumers}

While the paradigmatic consumer of modern theory consumes essentially in private, with a utility function that shows independence of the actions of other agents, economists have not completely ignored the possibility of interdependencies in consumption; it has a history going back at least to Smith. This work can be split into two parts: the effects of a consumer's own consumption history on his/her current consumption; and the effects of the consumption patterns of peers and rivals. This mirrors the distinction made by Becker (1996) between the roles of personal capital and social capital in shaping tastes in consumption.

\subsection{The consumer's past consumption history}

An agent's history can create inertia in consumption patterns. Duesenberry (1949) recognized that when incomes fall, families run down savings to maintain the standard of consumption to which they have become accustomed. Brown (1952) modelled habit formation in demand behaviour as a positive autoregressive component in a traditional demand model. Friedman's concept of permanent income can also be seen in this tradition. $^{1}$ By contrast, some areas of economic theory (for example Dasgupta and Stiglitz, 1980), recognize that individual consumers can have a demand for variety. While the origin of the demand for diversity is not developed in detail, it can be

1 There have been some important subsequent contributions on the endogeneity of preferences for example, Becker and Murphy, 1988; Donckner and Feichtinger, 1993; Feichtinger et al, 1995; Gorman, 1967; Gintis, 1974; Pollak, 1970; von Weizacker, 1971. 
interpreted in the current context as a desire on the part of the consumer to differentiate his or her current consumption patterns from those of the past.

Most of the literature in this tradition has focussed on micro-economic results, with less concern on detailed macro-economic consequences, (and especially dynamic consequences), that follow from them.

\subsection{Consumption patterns of peers and rivals}

As noted above, Smith, Senior, Marshall and other classics recognized the consumer's desire to be distinctive. In Veblen's (1899) theory of conspicuous consumption, consumption is an activity undertaken to transmit a signal rather than simply to satisfy needs. Conspicuous consumption requires that individuals indulge in consumption activities recognized by their peers. But it also requires that they distinguish their consumption from that of ordinary people. And indeed, it is not enough that consumption simply imitates that of the peer group: there must be imitation and innovation, so that the individual occupies a distinctive place in the group. ${ }^{2}$ One interpretation of the desire for distinction is that consumers interact with each other outside the market, and that these interactions affect utility directly.

There is a now a growing body of literature concerned with direct interactions among agents in the economy. Kirman (1997) and Durlauf (1997) provide recent reviews with different emphasis. The work in this literature tends not to be about consumption as such, but is related to our concerns in that it addresses the issue that non-market interactions can affect the utilities (or productivities) of agents. This intuition has been applied to economic growth (Durlauf, 1993); discrete choice problems (Durlauf and Brock, 1995); opinion formation (Kirman, 1993); technology choice (An and Keifer, 1995) to name a few. In general, the concern in this work tends to be with equilibrium, and with equilibrium defined in relatively aggregated variables, such as, for example, the proportion of the population using a technology or holding an opinion. In some related regional models there is also a concern with the size of agglomerations (Cowan and Cowan, 1998). In general, though, the spaces in these models do not have direction. Externalities are often distance dependent but agents cannot be distinguished in any other way. To allow for distinction and aspiration effects, though, an agent must be able to distinguish between agents on his left and those on his right. Direction does matter. This paper models this aspect of space, which allows us to have a richer equilbrium concept, (and co-relative dynamic concerns) which involves the dis-

2 This idea re-appears in the work of Liebenstein (1950), Mason (1981), Earl (1986), Bagwell and Bernheim (1996), and Ireland (1994). 
tribution of consumption over the population of consumers in which consumer location is meaningful beyond distance from other consumers.

Some recent work on conformity and conventions has revisited the phenomenon of "fad" behaviour. ${ }^{3}$ Miller at al. (1993) — from a marketing perspective - make an important contribution 'Towards Formalising Fashion Theory' and some of the phenomena of aspiration and distinction described in this paper are also analysed there. ${ }^{4}$ Much of this work on conformity and convention, while examining peer, and to some extent distinction and aspiration effects, has focussed heavily on equilibria and the possibility of multiplicities. There has been significantly less attention paid to dynamics, however, and this is part of the goal of the present paper. It is also the case that much of the literture on fads and conformity relies heavily on information contagion. Fads and imitation take place because private information is considered inadequate for decisionmaking. Public information (and other agents' private information) is inferred from public behaviour, and this can create bandwagons or surges in activity, as common behaviour is interpreted as behaviour that has high payoff. We model a situation in which surges and waves in behaviour can arise even when all agents have good information about the properties of the good.

The type of interdependence driving consumption behaviour, with which we are concerned in this paper, can also be seen in the literature on de facto standards (Arthur, 1989; David, 1985; Farrell and Saloner, 1985; Cowan, 1991). The concept of network externalities (Katz and Shapiro, 1985) plays a central role in this literature, and recognizes that individual choices among competing products are be dependent on the consumption activities of others. In this literature, standards emerge because there are economies of scale in joint consumption. ${ }^{5}$ In this work, though, externalities tend to be very simple: they are only positive, and apply equally to all members of the economy. Put another way, there are only (positive) peer effects, and every agent is the peer of every other. ${ }^{6}$

To remove from the very strong standardization results of the technology choice literature, it is important to recognize heterogeneity among agents, even if only peer

\footnotetext{
3 See for example, Banerjee (1993); Bernheim (1994); Corneo and Jeanne (forthcoming); Young (1993). Granovetter and Soong, (1986) examined the evolution of patterns of consumption in a similar vein.

4 Other contributions to the economic analysis of fashion cycles include Bikhchandani et al (1992), Coelho and McClure (1993), and Pesendorfer (1995).

5 This is also recognized by Gaertner (1974).

6 Two recent exceptions to this characterization are Cowan and Cowan (1998) and David et al. (1998).
} 
effects are being modelled. Akerlof (1997) details a series of ethnographic studies and interpretations of peer effects (which he refers to as conformity effects) and their place in individual decision-making. He emphasizes the importance of heterogeneity in the population, particularly as regards location in a social space. Relative location has a vital impact on the nature of the externalities of one agent's behaviour on another. His concern, however, is equilibrium, and the simple models he presents make no attempt at dynamic analysis. They are simply used to illustrate the possible existence of multiple or inefficient equilibria.

The sociology of consumption (Douglas, 1975; Granovetter, 1978; Bourdieu, 1984) has made much progress in recognizing the social and interdependent nature of consumption. In Bourdieu's analysis (1984), taste is driven in part by the desire for distinction and peer group reference, and that gives rise to an explicitly evolutionary character of consumption patterns. But this last theory lacks the power of a quantitative modeling framework which an economic theory of consumption can bring.

While we have made a distinction between auto-referential and social interdependencies in consumption, they are in some respects comparable. The desire for social association has some similarity to the desire for auto-referential association (repetition or habit), and both tend to be positive interdependencies. Likewise, the desire for social distinction in consumption has something in common with the desire for auto-referential distinction (i.e. variety), and here both tend to be negative interdependencies.

The present paper, in contrast to most of the work cited above, focuses explicitly on dynamics. We provide analytic results not only on equilibria, but also on the dynamics by which equilibrium is reached. We draw particular attention to "waves" in consumption, their shape, duration and amplitude, and on the relationship between the form of external effects and the types of waves that occur. In contrast to much of the conformity literature, we generate these results from a model in which information is good, both about the properties of the good, and about what other agents are doing. Further, we add to the small, but growing, group of models with non-anonymous interactions. Pecuniary externalities are anonymous, in the sense that a price change affects all agents equally. Technical externalities are also generally modelled as having that property. In the present model this is not so- the behaviour of an agent affects different agents differentially. ${ }^{7} \quad$ While the paper is largely theoretical, the model we develop has considerable empirical relevance. As the next section shows, a wide variety

\footnotetext{
7 Kirman's (1997) review includes some of the literature dealing with non-anonymous interactions.
} 
of examples show waves in consumption that are similar to those that emerge in the model.

\section{Some Empirical Examples}

This section offers several illustrations of contexts in which consumption patterns are independent, and where it is common to find waves in consumption behaviour.

\subsection{Fine art}

One striking example of waves in demand, reflecting in part changing fashions, is in the prices of works of art (Reitlinger, 1961, 1970). Figure 1 shows for three ar tists an estimate of the prices of their works (sold at auction) over a long period. AlmaTadema, perhaps not especially well known today, had his heyday at the end of the 19th century and the start of the 20th century, when his work sold for higher prices than those of both Canaletto (an old master) and Cézanne. But after his death, with some high-brow critics holding unfavorable views of his work, his price fell steadily until about 1960. Cézanne's work, by contrast, was not highly priced during his lifetime, but prices took off very rapidly from the start of the 20th century, and have never turned back. Canaletto is singled out by Reitlinger as an artist whose market price has shown unusual cycles, partly due to changes in fashion, and partly due to competition from other "realistic" landscape painters, as they come in and out of vogue.

\section{f Price of Oil Paintings - 1970 Prices}

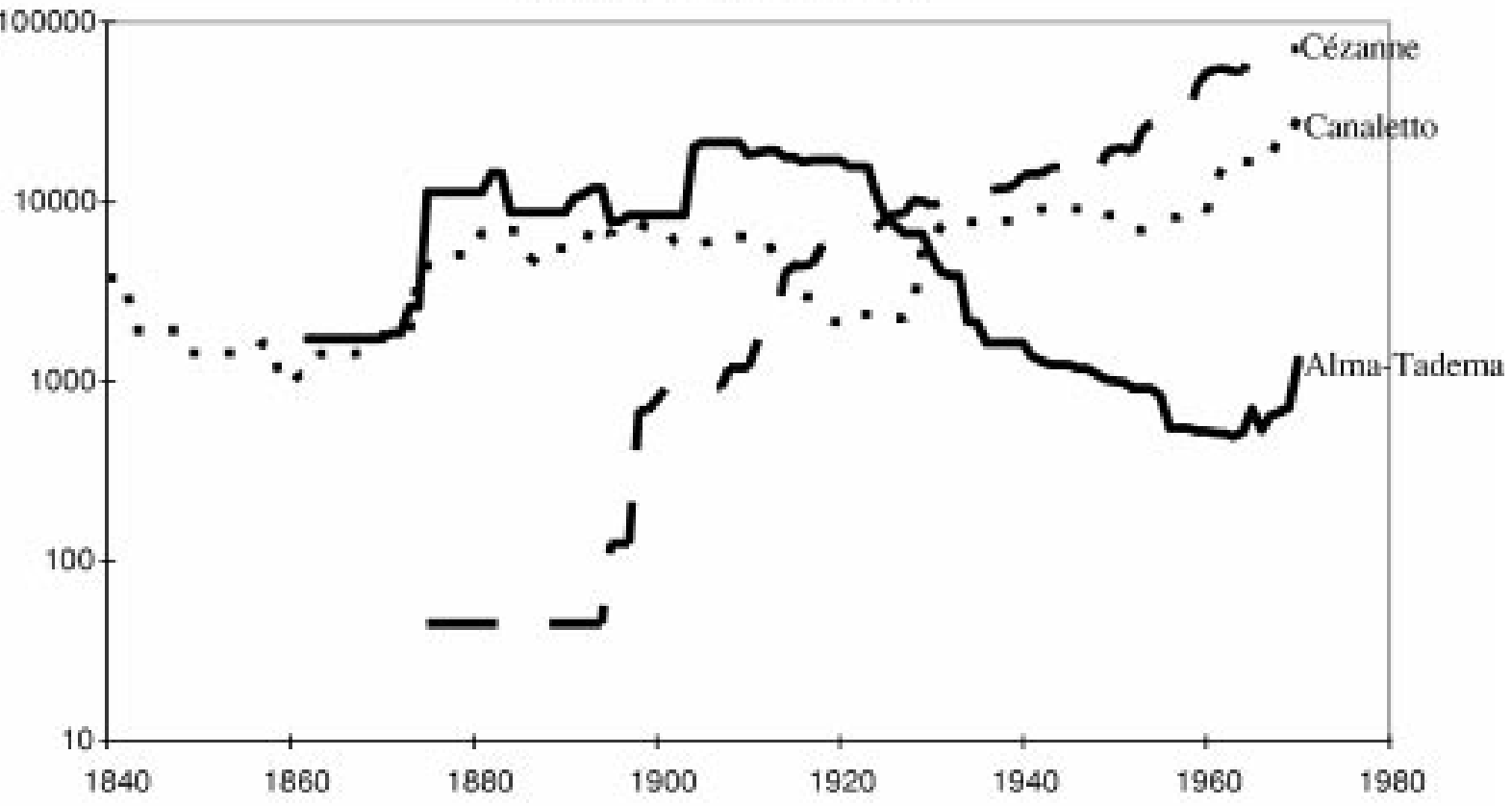

Source: Authors' calculations based on data in Reitlinger (1961,1970), Mitchell and Deane (1971) and Mitchell (1980)

Figure 1: Art Prices over Time, Showing Waves of Demand 
These fashion cycles are a striking example of the effects with which this paper is concerned. While it is difficult to map out in detail the popularity of these artists with different social classes, it is clear that the steady fall in the prices of works by AlmaTadema is attributable to the decision by a part of the artistic elite to distance themselves from the works of that artist. By contrast, the rapid rise in prices of Cézanne's work is attributable to the fact that pioneers in the artistic elite started to consider him an artist of great originality, and their tastes have been emulated by the popular art-lover. This last observation poses an interesting question about whether (and when) an artistic elite might seek to distance themselves from the too-popular impressionist painters, but this does not seem to have happened yet.

\subsection{Holiday resorts}

Waves in popularity exist in the market for holiday resorts. Some holiday makers seek resorts where they can be with chosen friends or peer groups, while others seek to keep away from the masses in popular (and down-market) resorts, a distinction effect. Yet others seek to take holidays where they brush with the rich and famous, an example of aspiration. The rich and famous in turn may wish to move away from the vulgar arrivistes. These patterns of differentiation and association make for an interesting dynamic. One possible outcome is cyclical popularity in holiday resorts. A new resort starts off as a distinctive and select venue, and hold this status for some years. It subsequently starts to seem vulgar in the eyes of the pioneers as it grows in popularity. It then goes distinctly down market, and many of the pioneering elite holiday-makers are driven out. Finally, when the resort has been unfashionable for many years, it can enjoy a renaissance. When the unattractive associations from which early holidaymakers sought refuge are far enough in the past, a new sort of pioneer can start off a second wave of popularity. A striking example of the rise and fall of a holiday resort is offered by the history of the English spa town, Bath. Smith (1948, p. 75) describes how Bath rose to become a most fashionable centre, but noted that: "its very popularity was the primary cause of its gradual decline. For when Bath was invaded by the mob, it ceased to attract its aristocratic clientele, and to be the chosen resort of Polite Society." Here we see a clear example of distinction and almost certainly aspiration effects. The model described below can be used to interpret this sort of decline of a holiday resort, and the dynamics of demand throughout its life.

\subsection{Residential neighbourhoods}

A related area of interdependence in consumption, which borders closely on the analysis of interdependence in production, is the emergence and decline of different areas of a city. Some areas that are currently very fashionable have more humble 
origins. Chelsea, in London, provides an excellent example. Equally, working in the other direction, ghettos can form out of formerly respectable areas (Durlauf, 1994; Schelling, 1971). This process is of course very close to the concept of clustering (or agglomeration) in production. Vibrant clusters form because of externalities in colocation, while moribund clusters decay when they are populated by old industries generating few positive externalities and many negative ones.

\subsection{Wine consumption}

Tomlinson and Swann (1998) have examined class patterns in the consumption of wine in Britain. While in many other European countries, wine is the people's drink, in Britain it has long been concentrated in the upper and middle classes. In recent years however, wine has formed a larger share of total alcohol consumption for all classes in the UK. Table 1, taken from Tomlinson and Swann (1998) shows that the "class differential" for total wine consumption has remained constant over a ten year period. When we divide total wine consumption into that consumed at home, and that consumed away from home (e.g. in restaurants and wine bars) then different patterns emerge. The class differential for wine consumed at home, which was relatively large, has grown even larger. By contrast, the class differential for wine consumed away from home, which was relatively small, has narrowed.

\section{Trends in Wine Consumption by Class of Consumer, UK} Figures show wine consumption as a percentage of all alcohol consumption

\begin{tabular}{lcccc} 
& \multicolumn{2}{c}{$\begin{array}{c}\text { Professional, Managerial } \\
\text { and Non-Manual Workers }\end{array}$} & $\begin{array}{c}\text { Manual } \\
\text { Workers }\end{array}$ & $\begin{array}{c}\text { Class } \\
\text { Differential }\end{array}$ \\
All Wine & $1983-1985$ & $25.4 \%$ & $10.9 \%$ & $14.6 \%$ \\
& $1991-1993$ & $28.9 \%$ & $14.4 \%$ & $14.4 \%$ \\
Wine at Home & $1983-1985$ & $15.0 \%$ & $6.3 \%$ & $8.7 \%$ \\
& $1991-1993$ & $19.6 \%$ & $8.6 \%$ & $11.0 \%$ \\
Wine Away from Home & $1983-1985$ & $10.4 \%$ & $4.6 \%$ & $5.8 \%$ \\
& $1991-1993$ & $9.3 \%$ & $5.8 \%$ & $3.5 \%$
\end{tabular}

Source: Tomlinson and Swann (1998)

While the model presented in this paper is a one-good model, and does not explicitly analyze how consumers may switch from one product to another, this observation is still interesting. While the observation is open to several interpretations, it is consistent with the idea that some groups of consumers seek to maintain a distinction from other 
groups. If one axis of differentiation is eroded (wine away from home) then they will seek to increase their distinction along another axis (wine consumed at home).

\subsection{The automobile market}

Swann (1997) has made an exploratory analysis of the demand for two types of prestige car - the Rolls Royce and the Ferrari. This analysis suggests two polar types of demand for distinction: distinction through antiquity and distinction through novelty. In the first case, upper class demand is strongest for the older vehicle, to distinguish the owner from the nouveau riche driver who prefers a new machine. Aggregate demand may be stronger for the new vehicle than it is for the classic vehicle, but in some segments that ordering is reversed. In the case of distinction through novelty, by contrast, demand is strongest for the latest, and most exciting model. In either case, there will be a subtle cycle of demand for cars of different vintages. This perspective also offers an interesting insight into the importance of frequent design changes in prestige cars. Given the role of prestige cars as signals of social position, it is essential that the cognoscenti who buy the most prestigious vehicle are confident that their peers recognize their vehicles as the best. If the car is not sufficiently distinctive, then it is not fulfilling its function.

\subsection{China and managed diffusion}

Josiah Wedgewood, sometimes referred to as the first capitalist, understood the importance of aspiration effects. He discussed the popularity of his china with Thomas Bentley:

It is really amazing how rapidly ... [our china] has spread over almost the whole Globe, \& how universally it is liked. How much of this general use, \& estimation, is owing to the mode of its introduction \& how much to its real utility \& beauty? are questions in which we may be a good deal interested for the government of our future Conduct ... For instance, if a Royal, or Noble Introduction be as necessary to the sale of an Article of Luxury as real Elegance \& beauty, then the manufacturer, if he consults his own interest will bestow as much pains, \& expence too if necessary, in gaining the former of these advantages, as he would in bestowing the latter.

Josiah Wedgewood to Thomas Bentley, Sept. 1767, E. 18167-25, Wedgewood MSS, Keele University Library. (Emphasis in original.), quoted in McCraw (1997, p.20). 
One further example, television viewing behaviour, is subject to strong interdependencies. Habit formation is an important phenomenon and moreover there are significant class differences in viewing behaviour (Swann and Tavakoli, 1994). There are obvious "viewing peer groups" with whom consumers choose to associate: friends and colleagues with whom they discuss and share what they have watched. There are also powerful distinction effects: some viewers do not want to be mistaken for the sort of person that might watch a low-brow game show. These effects have also had implications for the comparative diffusion of satellite TV and cable TV in the UK. The former is conspicuous (because of the aerial) while the latter is inconspicuous. If satellite TV is at an early stage positioned as a lower middle class consumption activity, then the middle classes who wish to avoid the disapproval of their geographical neighbours will be reluctant to indulge in the conspicuous activity of viewing satellite TV. They may be willing to indulge in the less conspicuous activity of subscribing to cable, however.

As is clear from the diversity in the examples, peer, aspiration and distinction effects exist in many different places. Their presence has generalizable effects on the evolution of consumption, and these effects are the subject of the model in the next section.

\section{A Model of Inter-dependencies in Consumption}

Schematically, the model works as follows. At time zero a good appears. Its consumption is distributed over a population of consumers, and initially the probability that a consumer of type $s$ consumes the good is given by $p(s, 0)$. The genesis of this distribution is unspecified. At each moment, some consumers are able to re-evaluate their past decisions, and re-decide whether to consume, doing so if consumption provides positive utility. Utility is generated by the objective properties of the good, externalities from other consumers as discussed above, and by a random component, idiosyncratic to each consumer. Thus the distribution of consumption evolves over time, as consumers change their behaviour in accordance with the actions of nearby consumers and the realization of a random variable. We address both the steady state and the dynamics of the system.

There is a continuum of consumers, distributed over the real line, indexed by $s$. The scalar $s$ is an incomplete representation of an agent in that it is insufficient information to predict behaviour, which implies that we can make only probabilistic statements about it. We refer to $s$ as "social status", and assume that it is unchanging 
over time. ${ }^{8}$ Consumers are faced with a choice between consuming and not consuming a single good. Utility from consumption has three sources: there is utility inherent in the properties of the good itself - the degree to which a consumer gets utility from this good will depend on his type. For example, we might think that some kinds of consumers get considerable utility from holiday resorts in which classical music is a feature, whereas other types of consumers find this a negative feature, preferring jazz. The second source of utility is from externalities from the actions of other agents - the distinction and aspiration effects discussed above. Finally, there is an idiosyncracy to each consumer. That is, even though consumers of a single type, $s$, have a tendency to like a particular type of music, the degree to which a particular consumer does is idiosyncratic to him and may change from period to period.

For a consumer of type $s$, utility from consumption can then be written as

$$
U(s, t)=f\left(s, p\left(s^{\prime}\right), t\right)+g(s)+\epsilon_{s, t},
$$

where $p\left(s^{\prime}, t\right)$ represents the actions of other consumers, $f\left(s, p\left(s^{\prime}, t\right)\right)$ captures peer, distinction and aspiration effects; $g(s)$ indicates the inherent value of the good to consumers of type $s$; and $\epsilon_{s, t}$ is the realization of a random variable representing the idiosyncratic component of utility. We assume that $\epsilon$ has a symmetric distribution, and without loss of generality, a mean of zero. Each period a proportion of consumers, $\alpha<1$, re-chooses whether to consume or not.

If the economy starts out of equilibrium, the following dynamics will exist:

$$
p(s, t+\Delta t)=(1-\alpha) p(s, t)+\alpha p^{*}(s, t+\Delta t)
$$

where $p(s, t)$ is the proportion of consumers of type $s$ who consume in period $t$; and $p^{*}(s, t+\Delta t)$ is the proportion of those who re-consider who opt to consume.

\section{Rewriting:}

$$
p(s, t+\Delta t)-p(s, t)=\alpha\left(p^{*}(s, t+\Delta t)-p(s, t)\right) .
$$

A consumer will consume if he gets positive utility from consumption. (This is equivalent to assuming a price of zero for the good. This assumption can be made

${ }^{8}$ We use the term "social status" as it fits well with the sociological literature on demand determination. This single dimension of heterogeneity could as easily be income, education,... That the model uses a scalar to describe agents indicates that they are quite incompletely specified. Agents can be more completely specified by increasing the dimension of $s$. In principle the analysis is identical, (provided there is always some incompleteness in the specification, as seems likely) but has the cost of considerable notational and analytical inconvenience. 
without loss of generality.) Ex ante, since $\epsilon$ is a random variable, we can discuss the evolution of the probability that a consumer of type $s$ consumes. For an arbitrary $s$ type, since the distribution of consumers is dense, this will be equal to the proportion of consumers of type $s$ who consume. Consumers choose simultaneously, which means they must make their decisions about the next period on the basis of current knowledge. Following the tradition of evolutionary game theory, we assume that consumers have myopic expectations. (Given that an agent with rational expectations would have to solve simultaneously the problem of every agent, this seems perfectly reasonable, the more so as $\alpha$ gets small.)

The function $p\left(s^{\prime}, t\right)$ describes the proportions of agents of each type consuming in that period. Based on that information, an agent will calculate a value for $f\left(s, p\left(s^{\prime}, t\right)\right)+$ $g(s)$ with which to make a decision when $\epsilon$ is realized. If $f\left(s, p\left(s^{\prime}, t\right)\right)+g(s)+\epsilon_{s, t}>0$ then the agent will consume in the next period. Of those agents free to change their decisions between $t$ and $t+\Delta t$, what proportion will consume? This is equal to the probability that $\epsilon>-\left(f\left(s, p\left(s^{\prime}, t\right)\right)+g(s)\right)$.

Thus we can write

$$
\begin{gathered}
p^{*}(s, t+\Delta t)=\operatorname{Pr}\left(\epsilon>-\left(f\left(s, p\left(s^{\prime}, t\right)\right)+g(s)\right) ;\right. \\
p^{*}(s, t+\Delta t)=R\left(f\left(s, p\left(s^{\prime}, t\right)\right)+g(s)\right) .
\end{gathered}
$$

The function $R(\cdot)$ is the cumulative distribution of $\epsilon$, and will have a standard ogive shape. To obtain analytic results we approximate this by the following: for nonextreme values $R(x)=a+b x$, with $R(0)=a=1 / 2$ and $b>0$. For large values, $x>x_{H}, R(x)=1$; for small values, $x<x_{L}, R(x)=0 .^{9}$

Thus

$$
p^{*}(s, t+\Delta t) \approx 1 / 2+b\left(f\left(s, p\left(s^{\prime}, t\right)\right)+g(s)\right)
$$

Substituting this into the dynamics from above,

$$
p(s, t+\Delta t)-p(s, t)=\alpha\left[1 / 2+b f\left(s, p\left(s^{\prime}, t\right)\right)+b g(s)-p(s, t)\right]
$$

or,

$$
p(s, t+\Delta t)-p(s, t)=\alpha b f\left(s, p\left(s^{\prime}, t\right)\right)+\alpha(1 / 2+b g(s)-p(s, t)) .
$$

${ }^{9}$ In the analytic results that follow, we restrict attention to systems in which boundary effects are not important. With this restriction we need not consider the possibility that agents have consumption probabilities of either zero or one. 
This difference equation describes the dynamics of the system. Dividing by $\Delta t$ and taking the limit, we can write equation 7 as a differential equation, in which $\alpha$ is the rate at which agents re-consider their actions:

$$
d p(s, t) / d t=\alpha b f\left(s, p\left(s^{\prime}, t\right)\right)+\alpha(1 / 2+b g(s)-p(s, t)),
$$

or

$$
d p(s, t) / d t=F\left(s, p\left(s^{\prime}, t\right)\right)+\alpha\left(p_{n}(s)-p(s, t)\right),
$$

which is the expanded form of

$$
d p(s, t) / d t=\alpha\left[p^{*}(s, t)-p(s, t)\right]
$$

Equation 9 fully describes the dynamics, and can be solved for the steady state of the system. It can also be used to examine properties of the path to the steady state. Before proceeding on those lines, however, we can immediately write one proposition regarding the steady state.

Proposition 1: In the absence of inter-consumer interaction (externalities in consumption) the equilibrium probability that type $s$ consumes the good is $p_{n}(s)$.

Inter-consumer interaction is contained in the term $F\left(s, p\left(s^{\prime}, t\right)\right)$, so in its absence the dynamics become $d p(s, t) / d t=\alpha\left(p_{n}(s)-p(s, t)\right)$, which is a simple partial adjustment model, converging to $p_{n}(s)$.

This proposition provides an interpretation of $p_{n}(s)$. It can be interpreted as the "natural distribution" of consumption. It is the distribution that would prevail if there were no externalities, and so flows entirely from the features of the good and the correlation between taste for those features and the value of $s$.

To derive further results regarding both the steady state and the dynamics of the system, we specify more completely the interaction or externalities among consumers. Above, we spoke of distinction, peer and aspiration groups, each group providing different types of externalities. We generalize this now to allow a consumer to be affected by externalities from any other member of the population. Dropping momentarily the time argument, we write the interaction effect on a consumer of type $s$ as $^{10}$

$$
F\left(s, p\left(s^{\prime}\right)\right)=\int_{-\infty}^{\infty} \bar{F}\left(s, s^{\prime}\right) p\left(s^{\prime}\right) d s^{\prime} .
$$

\footnotetext{
10 Note that in the derivation above, $F(\cdot)=\alpha b f(\cdot)$. We maintain the $F$ notation here only to facilitate exposition.
} 
The function $\bar{F}\left(s, s^{\prime}\right)$ measures the degree to which the consumption by an agent of type $s^{\prime}$ makes the good attractive to an agent of type $s$. Of course $\bar{F}(\cdot)$ can be positive or negative. This interaction term, $\bar{F}\left(s, s^{\prime}\right)$, can always be written as a sum of two functions: $\bar{F}\left(s, s^{\prime}\right)=F_{0}\left(s-s^{\prime}\right)+F_{1}\left(s, s-s^{\prime}\right)$. The second term will be nonzero if the nature of the externalities differs depending on the status of the consumer. For the analysis that follows, we assume that $F_{1}(\cdot)=0$ so we can write $F\left(s, p\left(s^{\prime}\right)\right)=$ $\int_{\infty}^{\infty} F_{0}\left(s-s^{\prime}\right) p\left(s^{\prime}\right) d s^{\prime}$. This assumption has implications regarding the extremes of the distribution of agents. Virtually all sources of heterogeneity that might impinge on consumption decisions have finite support. There is a richest person in the world, and his income or wealth is finite. For agents near the extremes of the support of the heterogeneity, (those with large or small $s$ ) $F_{1}$ will differ from that of those away from the extremes. Because the richest person has no one above him, there will be boundary effects which must be taken into account when treating his behaviour. The reaction of the richest person to the fact that he is on a boundary will in general be visible for a certain distance away from the boundary, as his "altered" behaviour will affect the behaviour of those just beneath him in wealth. (Similarly for the poorest person.) In this paper we will not make any attempt to incorporate this sort of effect, which must be done through $F_{1}$. We are thus restricting our attention to agents away from the extremes of the support. This can be seen as equivalent to assuming unbounded support.

We can now write the dynamics, equation 9 , as:

$$
d p(s, t) / d t=\int_{-\infty}^{\infty} F_{0}\left(s-s^{\prime}\right) p\left(s^{\prime}, t\right) d s^{\prime}+\alpha\left(p_{n}(s)-p(s, t)\right)
$$

Solving equation 11 is done by transforming both $s$ and $t$. (See the appendix for details.) A Fourier transform on $s$ and a Laplace transform on $t$ generate the conjugate variables $k$ and $z$ respectively: $P(k, z)=\int_{-\infty}^{\infty} e^{-i k s} \int_{0}^{\infty} e^{i z t} p(s, t) d t d s$. Following the derivation in the appendix, we can write the solution in terms of $k$ as

$$
\mathcal{P}(k, t)=\frac{\alpha P_{n}(k)}{\alpha-\mathcal{F}_{0}(k)}-\frac{\alpha P_{n}(k)-\left(\alpha-\mathcal{F}_{0}(k)\right) \mathcal{P}(k, 0)}{\alpha-\mathcal{F}_{0}(k)} e^{-\left(\alpha-\mathcal{F}_{0}(k)\right) t},
$$

where we define $\mathcal{F}_{0}(k)=\int_{-\infty}^{\infty} e^{-i k s} F_{0}(s) d s, \mathcal{P}(k, t)=\int_{-\infty}^{\infty} e^{-i k s} p(s, t) d s$ and $P_{n}(k)=$ $\int_{-\infty}^{\infty} e^{-i k s} p_{n}(s) d s .^{11}$

11 The following transformation retrieves the dependence of the probability on $s: p(s, t)=$ $\int_{-\infty}^{\infty} e^{i s k} \mathcal{P}(k, t) d k$. This form is the most interesting one to display when the functions are completely specified, as is done in the next section. However, in the absence of specific func- 
Proposition 2: The equilibrium probability changes in a non-trivial way when interconsumer interaction is present. The actual equilibrium probability deviates from the "natural" probability according to

$$
\lim _{t \rightarrow \infty} \mathcal{P}(k, t)=\alpha P_{n}(k) /\left(\alpha-\mathcal{F}_{0}(k)\right),
$$

where $\mathcal{F}_{0}(k), \mathcal{P}(k, t)$ and $P_{n}(k)$ are defined as above.

This is a re-arrangement of equation 12, and follows from the appendix. If $F_{0}(s)=$ 0 , then $\mathcal{F}_{0}(k)=0$ and we recover proposition one, wherein the steady state distribution was the natural distribution. But if $F_{0}(s) \neq 0$ the proposition states that the distribution of consumption is "distorted" from the natural distribution. The larger are the externalities in consumption, the larger is the distortion. The precise nature of the distortion will obviously depend on the nature of $F_{0}\left(s-s^{\prime}\right)$. Several illustrations are given in the next section.

Both propositions one and two deal with the steady state of the system. Propositions three and four deal with the path to the steady state solution.

Proposition 3: When $F_{0}\left(s-s^{\prime}\right)$ is an even function (consumers react identically to those higher and lower in the status distribution, i.e. $\left.F_{0}\left(s-s^{\prime}\right)=F_{0}\left(s^{\prime}-s\right)\right)$ the dynamic behaviour of the distribution is strictly diffusive: the initial state spreads continuously in status and decays exponentially while the equilibrium state builds up exponentially.

This can be seen by examining equation A4 in the appendix. It can be re-arranged to write

$$
\begin{aligned}
\mathcal{P}(k, t) & =\frac{\alpha P_{n}(k)}{\alpha-\mathcal{F}_{0}(k)}\left(1-e^{-\left(\alpha-\mathcal{F}_{0}(k)\right) t}\right)+\frac{\left(\alpha-\mathcal{F}_{0}(k)\right) \mathcal{P}(k, 0)}{\left(\alpha-\mathcal{F}_{0}(k)\right)} e^{-\left(\alpha-\mathcal{F}_{0}(k)\right) t} \\
& =\frac{\alpha P_{n}(k)}{\alpha-\mathcal{F}_{0}(k)}\left(1-e^{-\left(\alpha-\mathcal{F}_{0}(k)\right) t}\right)+\mathcal{P}(k, 0)\left(e^{-\left(\alpha-\mathcal{F}_{0}(k)\right) t}\right)
\end{aligned}
$$

In equation 13, the first term shows the growth of the final state (the final state as seen in Proposition 2); and the second term shows the decay of the initial state $p(s, 0)$.

An even valued function $F_{0}(s)$ means that the exponent $\alpha-\mathcal{F}_{0}(k)$ is real valued. Thus any intermediate state can be written as a sum of the decaying initial state and

tional forms it is less easy to interpret that the $k$-dependent function $P(k, t)$. To get an intuitive understanding of this form consider an arbitrary $s . P(k)$ measures the extent to which an agent at locations $s \pm \pi / k$ are influenced by the actions of agents of type $s$. Thus large values of $k$ indicate the importance of short range or local externalities whereas small values of $k$ indicate the importance of long range, or global externalities. 
the growing final state. (In general, the initial state changes shape as it decays and the final state changes shape as it grows.)

The proposition can be seen from the following argument. Fourier transforms and inverse transforms are unique, that is, if for two continuous integrable functions $f$ and $g$, if the transform of $f$ is equal to the transform of $g$, then $f=g$ (Walker, 1988, Theorem 4.17). Consider the sum of two functions: $u=v+w$ where $v$ and $w$ are respectively exponentially shrinking and growing in time: $v(s, t)=e^{a t} v(s, 0)$ and $w(s, t)=\left(1-e^{a t}\right) w(s, 0)$, with $a<0$. Transforming $u$ to $U$, creating the conjugate variable $k, U(k, t)=\int_{-\infty}^{\infty} e^{-i k s}\left[e^{a t} v(s, 0)+\left(1-e^{a t}\right) w(s, 0)\right] d s$. Noting that when $F_{0}(s)$ is an even function, $\alpha-\mathcal{F}_{0}(k)$ is real valued, this is the form of equation 13 , with $v(s, 0)$ being the inverse transform of $\mathcal{P}(k, 0)$ (in this case the initial state $p(s, 0)$ ); and $w(s, 0)$ being the inverse transform of $\alpha P_{n}(k) /\left(\alpha-\mathcal{F}_{0}(k)\right.$, which, by Proposition 2 , is the final state.

Proposition 4: When $F_{0}\left(s-s^{\prime}\right)$ is an odd function (consumers react inversely to those higher and lower in the status distribution, so $\left.F_{0}\left(s-s^{\prime}\right)=-F_{0}\left(s^{\prime}-s\right)\right)$ the dynamic behaviour of the system consists of travelling waves (peaks in the distribution that move in status with time), damped by $\alpha$, the rate at which consumers are able to change their behaviour.

This proposition follows from the following basic property of Fourier transforms. Consider a function $g(s, t)$ that is a simple travelling wave, so that $g(s, t)=g(s+$ $v t, 0)$, where $v$ is a parameter measuring the velocity of the wave. Transforming $s$ in period 0: $G(k, 0)=\int e^{-i k s} g(s, 0) d s$. In period $t, G(k, t)=\int e^{-i k s} g(s+v t, 0) d s$, which, by the change of variables $s^{\prime}=s+v t$ becomes $G(k, t)=\int e^{-i k\left(s^{\prime}-v t\right)} g\left(s^{\prime}\right) d s^{\prime}=$ $e^{i k v t} \int e^{-i k s^{\prime}} g\left(s^{\prime}\right) d s^{\prime}=e^{i k v t} G(k)$ which is exactly the form of equation $\mathrm{A} 4$ if $F_{0}(s)$ is odd, since in that case $\mathcal{F}_{0}(k)$ is imaginary.

Remark: All functions $F_{0}\left(s-s^{\prime}\right)$ can be written uniquely as sums of even and odd functions. When $F_{0}\left(s-s^{\prime}\right)$ contains both even and odd functions non-trivially, the solution is the sum of two solutions having the behaviours described in Propositions 3 and 4 . The qualitative features of this solution depend on the detailed form and value of the different parts.

These four propositions have dealt with very general properties of the dynamics and steady states of the distribution of consumption of a good. We can also use the model, though, to analyse why goods differ from each other in other aspects of consumption 
patterns. One observation that follows from the examples given above in section 3 is that some goods enter a population, move through it, and then disappear from it, but other goods enter, migrate through it, and find a stable niche. The next proposition addresses this observation.

Proposition 5: If $p_{n}(s)=0$ then the steady state distribution is that no consumers consume the good.

This follows directly from substituting $p_{n}(s)=0$ into the equilibrium distribution in proposition 2. If consumers gain no utility from the objective properties of the good, gaining utility only from the externalities, (that is, if it is a pure status or fad good) then the good will enter the population, migrate through it, and eventually disappear from it. Pet rocks, certain children's names, clothing fashions all provide examples. Conversely, if the objective properties of the good provide utility for some consumers $\left(p_{n}(s) \neq 0\right.$ for some $s$, then the good will be consumed by some consumers in equilibrium.

\section{Illustrations of the Model}

This section contains illustrations of the first four propositions of the previous section. Figure two shows the simplest case, corresponding to Proposition 1. Here there are no externalities in consumption, and agents decide whether to consume based solely on the properties of the good. As there is an assumed correlation between social status and taste for particular properties, this generates a 'natural' distribution over social status. The initial distribution of consumers, after the appearance of the good, is shown with a dotted line, the final, 'natural' distribution is shown with a solid line.

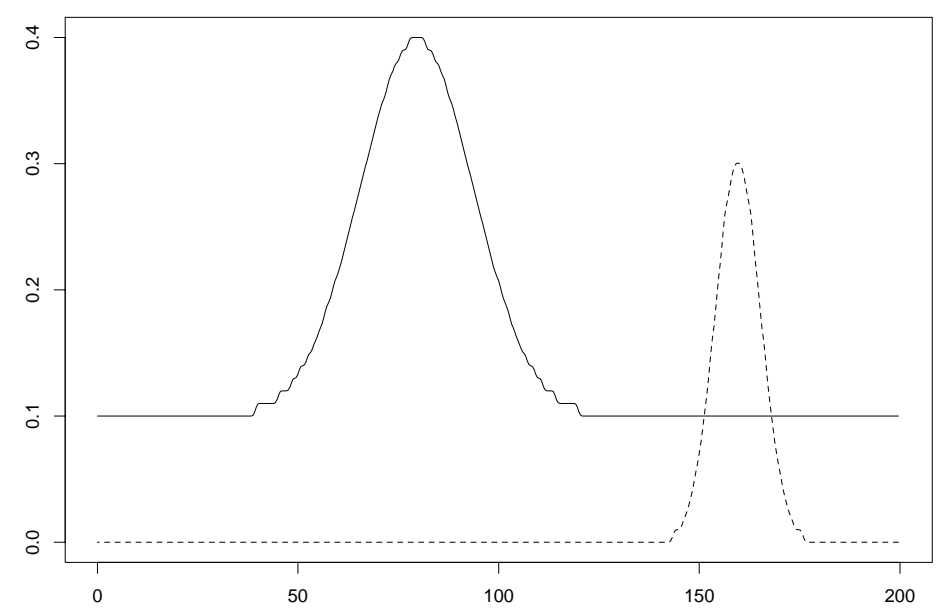

Figure 2: No Externalities in Consumption 
Figure three illustrates the changes that occur when externalities in consumption are present. $^{12}$ In this figure, an aspiration group exists, as does a distinction group. Thus consumers try to imitate those above them in social status, and distinguish themselves from those below In this example, the initial and natural distributions are the same as those in Figure 2. The final distribution is distorted from the natural one. Mass is distributed over more social states, and the peak is less pronounced. For these parameter values, the distribution in fact has two modes, though the mode nearer the mode of the 'natural' distribution is more pronounced. The mode here is shifted to the left, as consumption among the lower classes, driven by the natural distribution, reduces consumption of those just above. At the same time the peak is broader and flatter, as there is more mass away from its modal value.

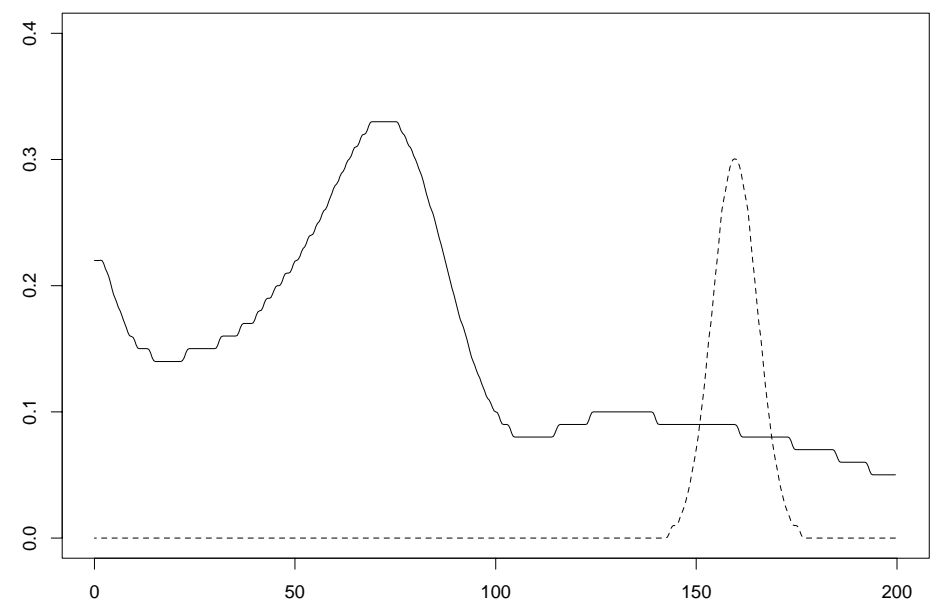

Figure 3: Distinction and Aspiration Effects

Figures 4, 5 and 6 illustrate propositions 3 and 4, and summarize three examples of the waves of demand that this model can generate. They show the pattern of demand as a function of class, and how this unfolds over time. In each case the simulations are run for 201 class segments and 300 time periods, and are examples of iterating equation 7. The graphs are drawn in the same style as relief maps in a geographical atlas. The darker the shading at a particular point on the graph, the more intense is demand in that class at that time.

12 In figures three through six, there are effects in the tails of the distribution that stem from the boundary considerations discussed above. The figures do not correspond with the model towards the bounds of the support, because, unlike the model, the figures have finite support, which implies that boundary effects will be present. These should be ignored while interpreting the figures as illustrations of the propositions. 
Figure four illustrates the dynamics of the system when $F_{0}(\cdot)$ is even, that is, when externalities are symmetric in the social space. Consumers gain positive externalities from those both above and below them, but the strength of the externality diminishes with distance. This could be considered a very powerful peer effect where most other consumers are thought of as peers, when $F_{0}\left(s, s^{\prime}\right)$ is positive. The figure shows a heavy initial consumption near the top of the class spectrum, which slowly simply diminishes in time. The natural distribution emerges quickly as a mode, and consumption at that class status simply increases over time. In this exercise there are no wave effects.

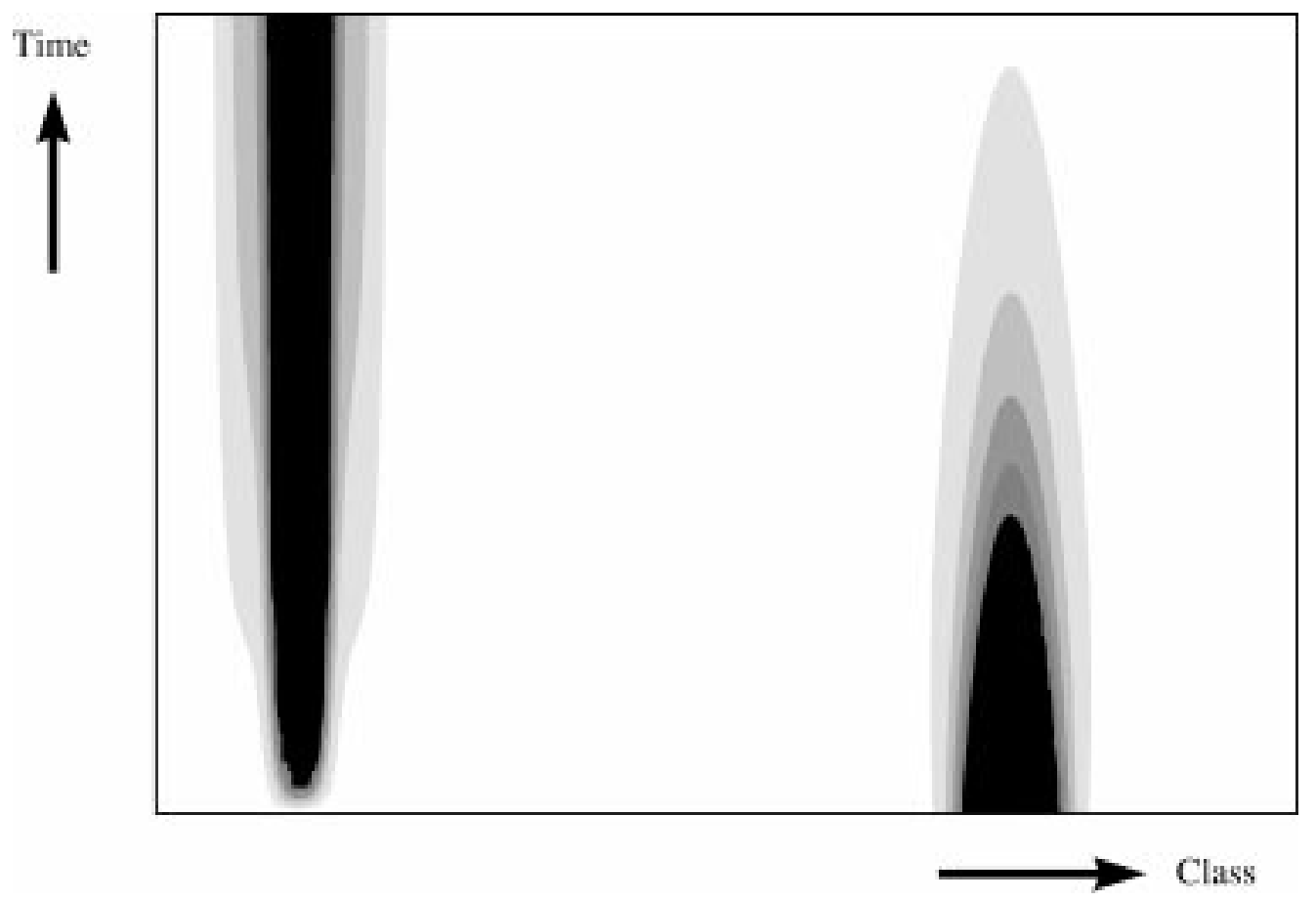

Figure 4: Evolution of Consumption

Symmetric externalities from nearby consumers $\left(F_{0}(\cdot)\right.$ even)

In figures 5 and $6, F_{0}\left(s, s^{\prime}\right)$ is odd. That is, consumers feel both distinction and aspiration effects. In both of these figures, consumers aspire to be like those above them in social class, and wish to distinguish themselves from those below. Thus they receive positive externalities from those above, and negative from those below. In figure 5 these effects decrease in strength as social distance increases, whereas in figure 6 they increase. The effects are, however, truncated at a finite distance. In both cases the first incidence of demand is at the upper end of the class spectrum, and demand gradually spreads down market. As demand spreads down to lower classes, the upper classes drop out of the market - as the distinction effect comes into play. Note that in both cases there remains a block of consumption at the bottom end of the class spectrum. This is the "natural distribution" described above, and it remains because the inherent 


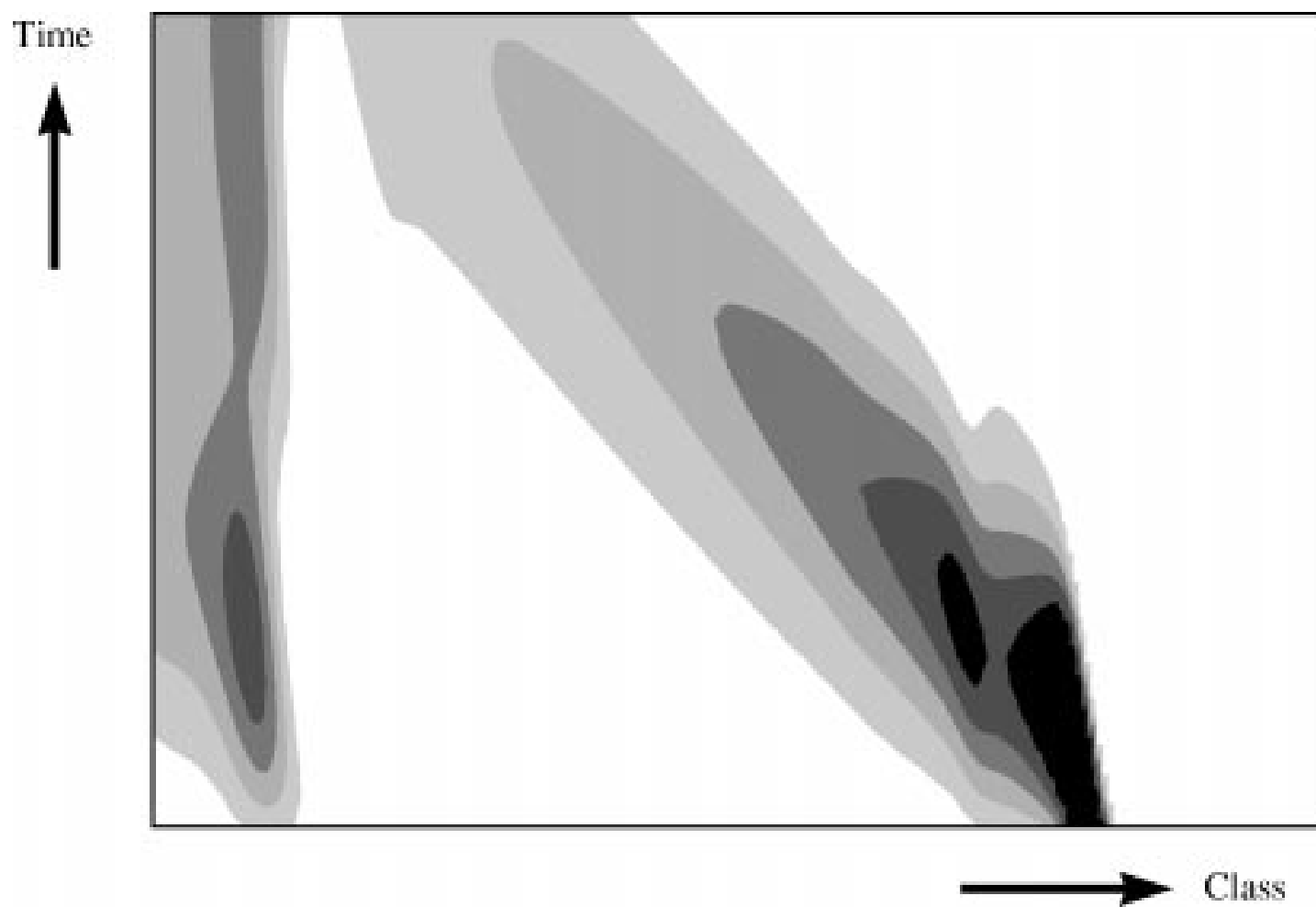

Figure 5: Evolution of Consumption

Asymmetric externalities from nearby consumers, $(F(\cdot)$ is odd), decreasing in distance.

properties of the good tend to give high utility to those near the bottom of the class spectrum.

The main difference between these two cases is in the "smoothness" with which demand spreads down-market. When the strength of the effect decreases with distance, the evolution of consumption is smooth in two senses. First, for almost any given class of consumer, demand as a function of time is single peaked: it increases to a maximum and then gradually fades away. Second, at any given time - and neglecting the block of consumption at the bottom end of the class spectrum - demand as a function of class is also single-peaked over a wide area of the graph. When the strength of external effects increase with distance, by contrast, (as in Figure 6) the evolution of consumption is much less smooth. Here there are a series of local maxima. Indeed, whether we look at demand as a function of time for a given class, or demand as a function of class at any given time, it is comparatively rare to find that these functions are single-peaked. On the contrary, there are many "echo effects" where demand grows, declines, and the reappears.

This distinction is important because while some waves of consumption are singlepeaked (e.g. Alma-Tadema in Figure 1, over the period 1860-1960) others are not (e.g. Canaletto in that figure). To model the range of consumption waves described in 


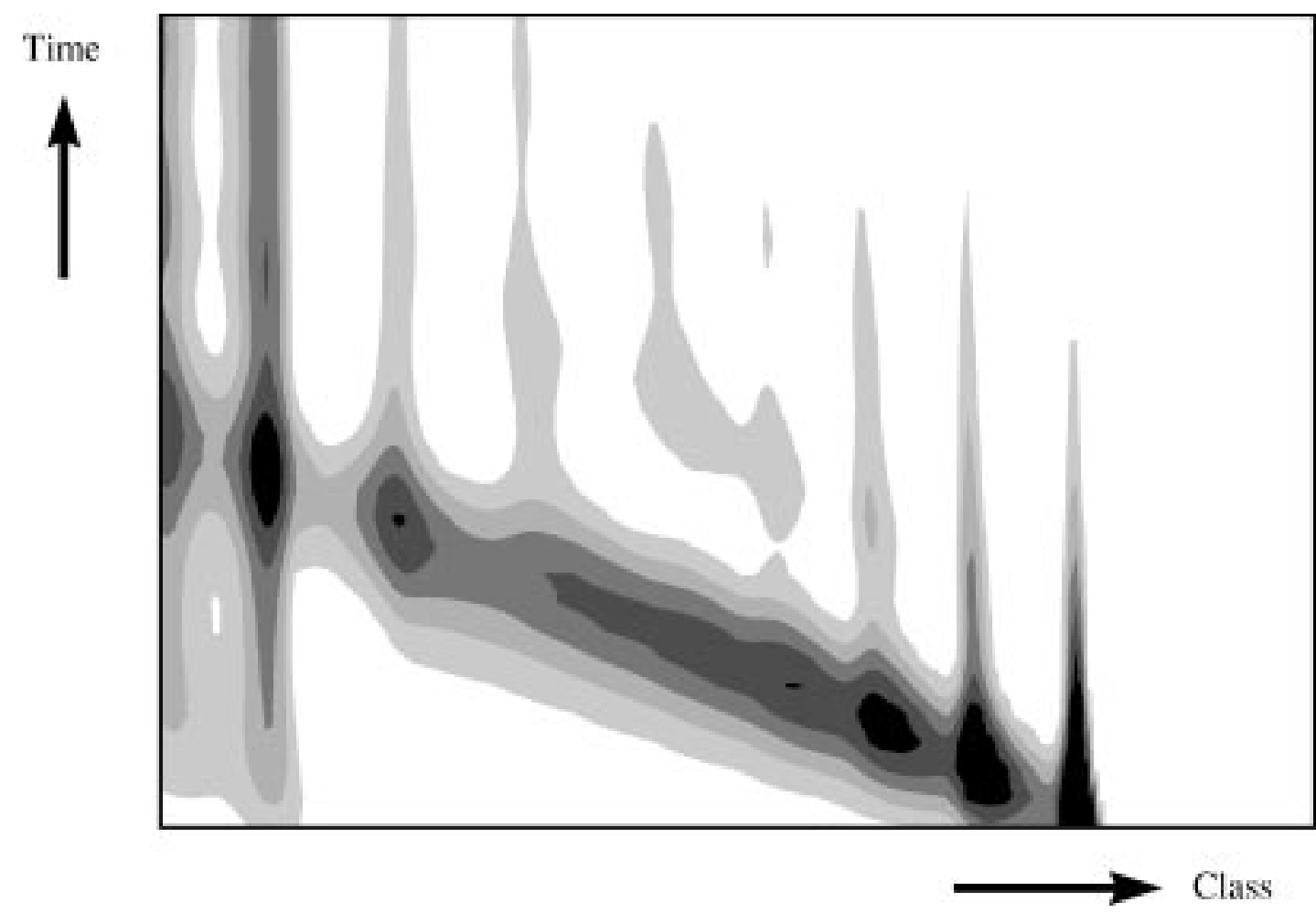

Figure 6: Evolution of Consumption

Asymmetric externalities from nearby consumers, $\left(F_{0}(\cdot)\right.$ is odd), increasing in distance.

Section 3 we need to be able to handle smooth waves and more volatile waves, and this suggests that the interdependency effects used in this paper need very careful empirical attention.

Even in the case of Figure 6, where the overall pattern of consumption does not evolve in a smooth manner, it is possible that the aggregate level of consumption is still smooth. Figure 7 illustrates this by integrating the consumption pattern of Figure 6 over the whole range of class segments, assuming a uniform distribution of consumers along the class axis. As is readily apparent, the aggregate demand function is (essentially) single peaked. But a different assumption about the distribution of consumers along the class line could generate a more volatile aggregate demand function. Figure 7 is useful when we seek to apply these models to analyze data of the sort presented in Figure 1, where we do not have systematic data of demand by class, but do have data on total demand, or market-clearing prices, which can be assumed to depend on demand in an obvious way.

\section{Conclusions}

This paper has explored the patterns of demand that emerge when there are social interactions among different consumers. We have concentrated attention on the case where consumer preferences are influenced by the consumption behaviour of three refer- 


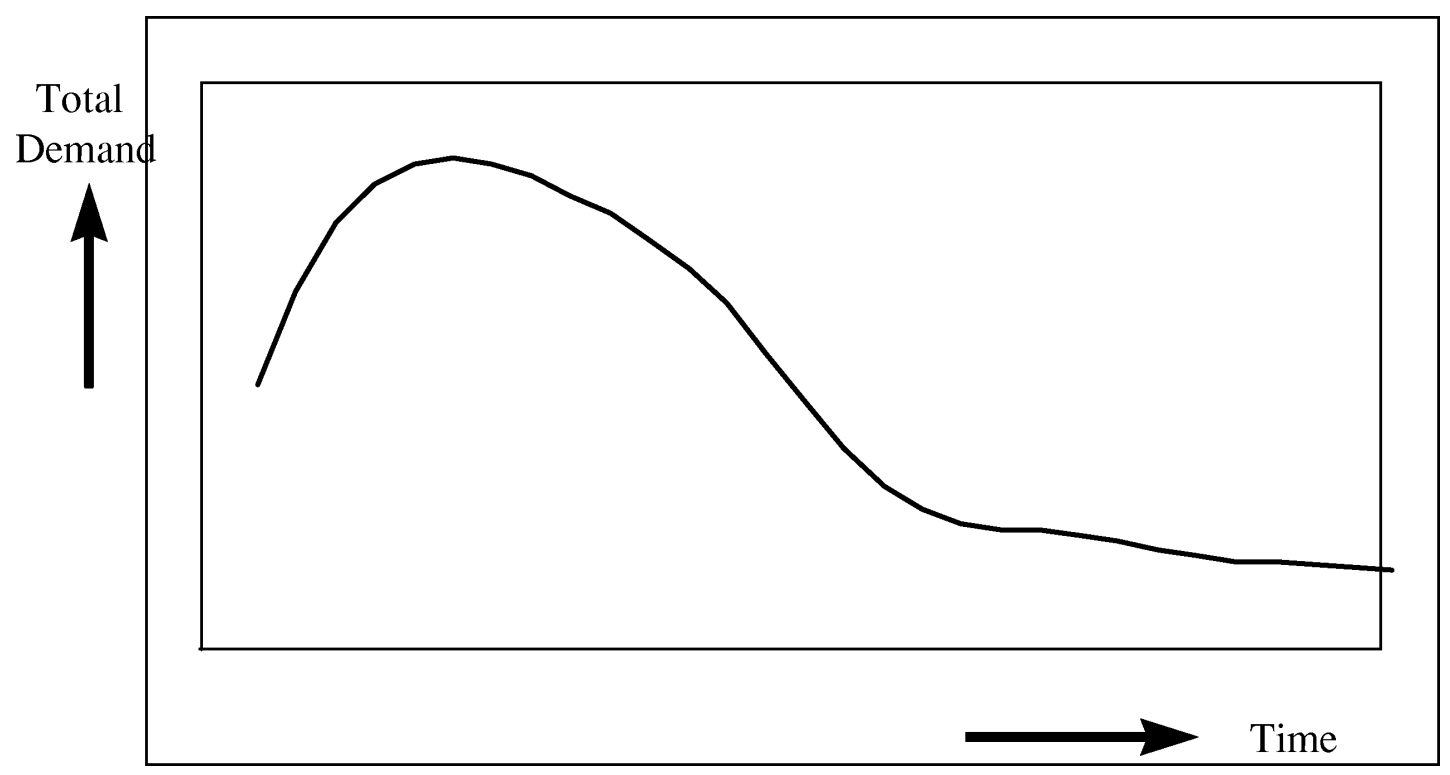

Figure 7: Evolution of Total Demand

ence groups: a peer group of similar consumers, with whom the individual shares some consumption activities; a contrast group (or distinction group), from which the individual wishes to distinguish him or herself; and an aspirational group, with whom the individual would like to share consumption activities, but cannot. The paper showed how this structure evolves over time and the nature of the state toward which it tends. The tension between the objective properties of the good and the externalities in consumption determine the final distribution of consumption over the attributes of agents. The nature of the externalities determines the properties of the evolution toward that state. The relevance and potential applications of this model were demonstrated by a number of illustrative examples. While these were only suggestive, and not rigourously researched, they suggest that consumer preferences are frequently influenced by at least one of the three reference groups, and that the patterns of consumption generated by the model are frequently found in practice. 


\section{References}

Akerlof G. (1997) “Social Distance and Social Decisions” Econometrica 65(5): 1005-27.

An, M. and N. Kiefer (1995). "Local Externalities and Societal Adoption of Technologies" Journal of Evolutionary Economics, 5, 103-117.

Arthur W. B. (1989) "Competing Technologies, Increasing Returns, and Lock-In by Historical Events" Economic Journal, 99, 116-131

Bagwell L.S. and B.D. Bernheim (1996) "Veblen Effects in a Theory of Conspicuous Consumption" American Economic Review 86(3), 349-373

Banerjee A.V. (1993) "A Simple Model of Herd Behaviour" Quarterly Journal of Economics 107. $77-817$

Becker, G.S. (1996) Accounting for Tastes Cambridge, MA: Harvard University Press

Becker G.S. (1991) "A Note on Restaurant Pricing and Other Examples of Social Influences on Price" Journal of Political Economy, 99, 1109-1116

Becker G.S. and K.M. Murphy (1988) "A Theory of Rational Addiction" Journal of Political Economy, 96, 675-700

Bernheim D. (1994) "A Theory of Conformity" Journal of Political Economy, 105, 841-877.

Bikhchandani S., D. Hirschleifer and I. Welch (1992) "A Theory of Fads, Fashion, Custom and Cultural Change as Informational Cascades" Journal of Political Economy, 100, $992-1026$

Bourdieu P. (1984) Distinction: A Social Critique of the Judgement of Taste London: Routledge Kegan Paul

Brock, W. and S. Durlauf (1995), "Discrete Choice with Social Interactions" University of Wisconsin at Madison.

Brown T.M. (1952) "Habit Persistence and Lags in Consumer behaviour" Econometrica 20, $355-71$

Coelho P.R.P. and J.E. McClure (1993) "Towards an Economic Theory of Fashion" Economic Enquiry, 31, 55-608

Corneo G. and O. Jeanne (forthcoming) "Snobs, bandwagons and the Origin of Social Customs in Consumer behaviour" Journal of Economic Behaviour and Organisation, forthcoming

Corneo G. and O. Jeanne (forthcoming) "Conformism, Snobbism and Conspicuous Consumption" Journal of Public Economics, forthcoming

Cowan R. (1991) “Tortoises and Hares: Choice Among Technologies of Unknown Merit" Economic Journal, 101, 801-814

Cowan, R. and W Cowan (1998) "On Clustering in the Location of R\&D: Statics and Dynamics" Economics of Innovation and New Technology, forthcoming.

Cowan R., W. Cowan and G. M. P. Swann (1997) "A Model of Demand with Interaction Among Consumers" International Journal of Industrial Organisation, 15, 711-732

Dasgupta P. and J. Stiglitz (1980) "Uncertainty, Industrial Structure and the Speed of R\&D" Bell Journal of Economics, 11, 1-28 
David P. A. (1985) "CLIO and the Economics of QWERTY" American Economic Review, 75, $332-336$

David, P.A., D. Foray and J-M. Dalle (1998). " Marshallian Externalities and technological Niches" Economics of Innovation and New Technology, forthcoming.

Donckner E.J. and G. Feichtinger (1993) "Cyclical Consumption Patters and Rational Addiction" American Economic Review, 83(1), 256-263

Douglas M. (1975) Implicit Meanings: Essays in Anthropology London: Routledge Kegan Paul

Duesenberry J.S. (1949) Income, Saving and the Theory of Consumer Behaviour Cambridge, Mass: Cambridge University Press.

Durlauf S.N. (1994) "Spillovers, Stratification and Inequality" European Economic Review, $38(3 / 4), 836-845$

Durlauf, S. (1993) "Nonergodic Economic Growth" Review of Economic Studies, 60, 349-366.

Durlauf, S. (1997) "Statistical Mechanics Approaches to Socioeconomic Behavior" in The Economy as a Complex Evolving System II, W.B. Arthur, S.N. Durlauf and D. Lane, eds., Redwood City: Addison-Wesley.

Earl, P.E. (1986) Lifestyle Economics: Consumer Behaviour in a Turbulent World Brighton: Wheatsheaf

Farrell J.R. and G. Saloner (1985) "Standardization, Compatibility and Innovation", RAND Journal of Economics, 16, 70-82

Feichtinger G., A. Prskewetz, W. Herold and P. Zinner (1995) "Habit Formation with Threshold Adjustment: Addiction May Imply Complex Dynamics" Journal of Evolutionary Economics, 5, 157-172

Friedman M. (1957) A Theory of The Consumption Function Princeton: Princeton University Press

Gaertner W. (1974) “A Dynamic Model of Interdependent Consumer Behaviour" Zeitschrift fr Nationalkonomie, 34, 327-44

Gintis H. (1974) "Welfare Criteria with Endogenous Preferences: The Economics of Education" International Economic Review 15, 415-30

Gorman W.M. (1967) "Tastes, Habit and Choices" International Economic Review, 8, 218-22

Granovetter M. (1978) "Threshold Models of Collective Behaviour" American Journal of Sociology, 83(6), 1420-1443

Granovetter M. and R. Soong (1986) "Threshold Models of Interpersonal Effects in Consumer Demand" Journal of Economic Behaviour and Organization, 7(1), 83-100

Ireland N. (1994) "On Limiting the Market for Status Signals" Journal of Public Economics $53,91-110$

Katz M. and C. Shapiro (1985) "Network Externalities, Competition and Compatibility" American Economic Review, 75, 424-440

Kirman, A. (1993) "Ants, Rationality and Recruitment" Quarterly Journal of Economic, 108, 137-156. 
Kirman, A. (1997) "Economies with Interacting Agents" in W.B. Arthur, S. Durlauf and D. Lane (eds.) The Economy as an Evolving Complex System, vol. 2, Addison Wesley.

Liebenstein H. (1950) "Bandwagon, Snob and Veblen Effects in the Theory of Consumers' Demand" Quarterly Journal of Economics, 65, 183-207

Marshall A. (1920) Principles of Economics, 8th Edition, London: MacMillan

Mason, R.S. (1981) Conspicuous Consumption: A Study of Exceptional Consumer Behaviour Aldershot: Gower Publishing

Miller, C.M, McIntyre, S.M. and Mantrala, M.K. (1993) 'Towards Formalising Fashion Theory' Journal of Marketing Research, 30, 142-151.

McCraw, Thomas, K. (1997). Creating Modern Capitalism, Harvard University Press.

Mitchell B.R. (1980) European Historical Statistics 1750-1975, Second Revised Edition, London: MacMillan Press Ltd

Mitchell B.R. with P. Deane (1971) Abstract of British Historical Statistics, Department of Applied Economics Monograph No. 17, Cambridge: Cambridge University Press

Pesendorfer W. "Design Innovation and Fashion Cycles" American Economic Review, 85, 771792

Pollak R.A. (1970) "Habit Formation and Dynamic Demand Functions" Journal of Political Economy, 78, 60-78

Reitlinger G. (1961) The Economics of Taste: The Rise and Fall of Picture Prices, 1760-1960, Volume I, London: Barrie and Rockliff [reissued 1982 by Hacker Art Books, Inc., New York]

Reitlinger G. (1970) The Economics of Taste: The Rise and Fall of Picture Prices, 1760-1960, Volume III, London: Barrie and Rockliff [reissued 1982 by Hacker Art Books, Inc., New York]

Schelling T. (1971) "Dynamic Models of Segregation" Journal of Mathematical Sociology, 1, $143-96$

Smith A. (1776) The Wealth of Nations

Smith R. A. L. (1948) Bath, 3rd edition, London: B.T. Batsford Ltd.

Swann G.M.P. and M. Tavakoli (1994) "An Econometric Analysis of Television Viewing, and the Welfare Economics of Introducing an Additional Channel in the UK" Information Economics and Policy, 6, 25-51

Swann, G.M.P. (1997) 'The Demand for Distinction and the Evolution of the Prestige Car' paper for Workshop on Escaping Statiation, Max-Planck Institut for Research into Economic Systems, Jena, Germany, December 11-13

Tomlinson M. and G.M.P. Swann (1998) "An Econometric Model of Class Effects in the Consumption of Wine" Unpublished Paper, CRIC, University of Manchester

Veblen T. (1899) The Theory of the Leisure Class: An Economic Study of Institutions New York: MacMillan

Walker, J.S. (1988). Fourier Analysis New York: Oxford University Press. 
Weizcker C.C. von (1971) "Notes on Endogenous Changes of Tastes" Journal of Economic Theory, 3, 345-372

Young P. (1993) "The Evolution of Conventions" Econometrica, 61, 57-84 


\section{Appendix}

In this appendix we present the derivation of the solution to equation 1 . The change in the probability that an agent consumes the good is given by

$$
\frac{d}{d t} p(s, t)=\int_{-\infty}^{\infty} F_{0}\left(s, s^{\prime}\right) p\left(s^{\prime}, t\right) d s^{\prime}-\alpha\left(p(s, t)-p_{0}(s)\right) .
$$

In order to solve this equation we transform the two varaibles, $s$ and $t$. A Fourier transform on $s$ and a Laplace transform on $t$ yield the conjugate variables $k$ and $z$ :

$$
P(k, t)=\int_{-\infty}^{\infty} e^{i k s} p(s, t) d t,
$$

and so

$$
P(k, z)=\int_{-\infty}^{\infty} e^{-i k s} \int_{0}^{\infty} e^{-i z t} p(s, t) d t d s .
$$

We assume that the imaginary part of $z, \operatorname{Im}(z)>0$ to ensure convergence.

Intregrating by parts with respect to $t$ and substituting for $d p(s, t) / d t$ gives:

$$
\begin{aligned}
P(k, z)=- & \frac{1}{i z} \int_{-\infty}^{\infty} e^{-i k s} p(s, 0) d s-\frac{1}{i z} \int_{-\infty}^{\infty} e^{-i k s} \int_{0}^{\infty} e^{i z t} \int_{-\infty}^{\infty} F_{0}\left(s-s^{\prime}\right) p\left(s^{\prime}, t\right) d s d s^{\prime} d t \\
& +\frac{1}{i z} \int_{-\infty}^{\infty} e^{-i z t} \int_{0}^{\infty} e^{i k s}\left(p(s, t)-p_{0}(s)\right) d s d t \\
= & -\frac{1}{i z} \mathcal{P}(k, 0)-\frac{1}{z^{2}} P_{0}(k)+\frac{1}{i z} P(k, z)-\frac{1}{i z} F_{0}(k) P(k, z)
\end{aligned}
$$

where

$$
\begin{aligned}
F_{0}(k) & =\int_{-\infty}^{\infty} e^{-i k s} F_{0}(s) d s \\
\mathcal{P}(k, 0) & =\int_{-\infty}^{\infty} e^{-i k s} p(s, 0) d s \\
P_{0}(k) & =\int_{-\infty}^{\infty} e^{-i k s} p_{0}(s) d s
\end{aligned}
$$

This can be re-arranged as

$$
P(k, z)\left(1-\frac{1}{i z}\left(\alpha-F_{0}(k)\right)\right)=-\frac{1}{i z} \mathcal{P}(k, 0)-\frac{\alpha}{z^{2}} P_{0}(k) .
$$

Thus

$$
P(k, z)\left(z^{2}+i z\left(\alpha-F_{0}(k)\right)\right)=i z \mathcal{P}(k, 0)-\alpha P_{0}(k)
$$

or

$$
P(k, z)=\frac{i z \mathcal{P}(k, 0)-\alpha P_{0}(k)}{z^{2}+i z\left(\alpha-F_{0}(k)\right)}
$$


To solve this we use the following manipulation: $\frac{A z+B}{z(z+C)}=\frac{X}{Z}+\frac{Y}{Z+C}=\frac{X Z+X C+Y Z}{Z(Z+C)}$ where $X+Y=A ; X C=B: X=B / C ; Y=A-B / C$. In our case, $A=i \mathcal{P}_{0}(k) ; B=$ $-\alpha P_{0}(k) ; C=i\left(\alpha-F_{0}(k)\right) ; X=i \alpha P_{0}(k) /\left(\alpha=F_{0}(k)\right)$ and $Y=i \mathcal{P}(k, 0)-\frac{i \alpha P_{0}(k)}{\alpha-F_{0}(k)}$. Thus we can write

$$
P(k, z)=\frac{i \alpha P_{0}(k)}{z\left(\alpha-F_{0}(k)\right)}+\frac{i\left(\alpha-F_{0}(k)\right) \mathcal{P}(k, 0)-i \alpha P_{0}(k)}{\left(z+i\left(\alpha-F_{0}(k)\right)\right)\left(\alpha-F_{0}(k)\right)} .
$$

Solving as a differential equation, the particular solution for $P(k, t)$ will be a constant. (In the steady state $P(k, t)$ is a constant, since $P(s, t)$ will be a constant.) Thus since $P(k, z)=\int_{0}^{\infty} e^{i z t} P(k, t) d t$, we can see that $P(k, z)=C_{1} \int_{0}^{\infty} e^{i z t} d t$, which gives that $P(k, z)=C_{1}(-1 / i z)$. From equation A2, this gives that

$$
C_{1}=\frac{\alpha P_{0}(k)}{\alpha-F_{0}(k)}
$$

We can write the general solution as $P(k, t)=C_{2} e^{-D t}$. We assume, again to assure convergence, that $\operatorname{Re}(D)+\operatorname{Im}(z)>0$. By the same argument,

$$
\begin{aligned}
P(k, z) & =C_{2} \int_{0}^{\infty} e^{-D t} e^{i z t} d t \\
& =C_{2}(-1) /(i z-D)
\end{aligned}
$$

From equation $\mathrm{A} 2$ we can see then that $D=\alpha-F_{0}(k)$ and that

$$
C_{2}=\frac{-\alpha P_{0}(k)+\left(\alpha-F_{0}(k)\right) \mathcal{P}(k, 0)}{\alpha-F_{0}(k)}
$$

Thus

$$
\mathcal{P}(k, t)=\frac{\alpha P_{0}(k)}{\alpha-F_{0}(k)}-\frac{\alpha P_{0}(k)-\left(\alpha-F_{0}(k)\right) \mathcal{P}(k, 0)}{\alpha-F_{0}(k)} e^{-\left(\alpha-F_{0}(k)\right) t}
$$

